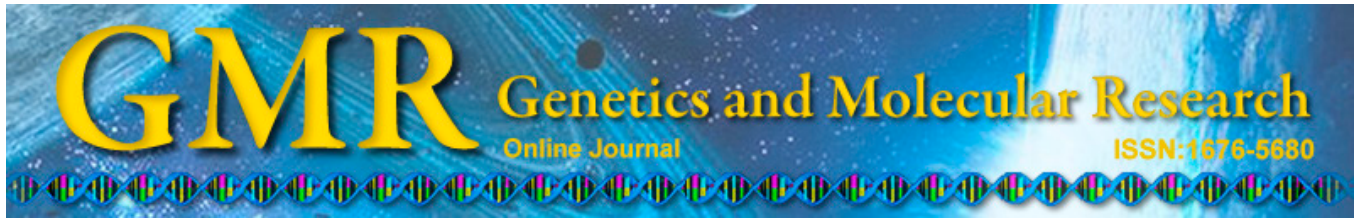

\title{
Functional molecular markers (EST-SSR) in the full-sib reciprocal recurrent selection program of maize (Zea mays L.)
}

\author{
K.S.C. Galvão, H.C.C. Ramos, P.H.A.D. Santos, G.C. Entringer, \\ J.C.F. Vettorazzi and M.G. Pereira \\ Laboratório de Genética e Melhoramento Vegetal, \\ Centro de Ciências e Tecnologias Agropecuárias, \\ Universidade Estadual do Norte Fluminence, Campos de Goytacazes, \\ RJ, Brasil \\ Corresponding author: M.G. Pereira \\ E-mail: messiasgpereira@gmail.com
}

Genet. Mol. Res. 14 (3): 7344-7355 (2015)

Received July 31, 2014

Accepted January 29, 2015

Published July 3, 2015

DOI http://dx.doi.org/10.4238/2015.July.3.10

\begin{abstract}
This study aimed to improve grain yield in the full-sib reciprocal recurrent selection program of maize from the North Fluminense State University. In the current phase of the program, the goal is to maintain, or even increase, the genetic variability within and among populations, in order to increase heterosis of the 13th cycle of reciprocal recurrent selection. Microsatellite expressed sequence tags (EST-SSRs) were used as a tool to assist the maximization step of genetic variability, targeting the functional genome. Eighty $\mathrm{S}_{1}$ progenies of the 13th recurrent selection cycle, 40 from each population (CIMMYT and Piranão), were analyzed using 20 EST-SSR loci. Genetic diversity, observed heterozygosity, information content of polymorphism, and inbreeding coefficient were estimated. Subsequently, analysis of genetic dissimilarity, molecular variance, and a graphical dispersion of genotypes were conducted. The number of alleles in the CIMMYT population ranged
\end{abstract}


from 1 to 6 , while in the Piranão population the range was from 2 to 8 , with a mean of 3.65 and 4.35 , respectively. As evidenced by the number of alleles, the Shannon index showed greater diversity for the Piranão population (1.04) in relation to the CIMMYT population (0.89). The genic SSR markers were effective in clustering genotypes into their respective populations before selection and an increase in the variation between populations after selection was observed. The results indicate that the study populations have expressive genetic diversity, which corresponds to the functional genome, indicating that this strategy may contribute to genetic gain, especially in association with the grain yield of future hybrids.

Key words: Zea mays; Genetic diversity; EST-SSR markers; Reciprocal recurrent selection

\section{INTRODUCTION}

Maize (Zea mays L.) is a cereal of great economic and social importance, and is cultivated in almost all agricultural regions in the world for food, feed, and more recently, as a source of biofuel. Currently, Brazil is the third largest producer of corn, being surpassed only by the United States and China (FAO, 2012).

Selection of the right hybrid is critical for maize producers in order to obtain high yields and satisfactory profits. It is important to periodically check the agronomic performance of the recommended hybrids for specific growing regions (Santos et al., 2002). Plant breeding is an indispensable tool in this process, allowing recombination of genes between divergent and superior genotypes, aiming to make the most of the genetic divergence in obtaining cultivars with high yields and adapted to different environmental conditions (Allard, 1971).

Plant breeding programs enable the use of classical methods, such as recurrent selection, with biotechnological procedures, including the use of DNA markers. The use of molecular markers in recurrent selection programs initially aimed to investigate changes in allele frequencies resulting from the selection inherent in this method (Labate et al., 1997; De Koeyer et al., 2001; Pinto et al., 2003a). However, the use of this molecular tool to assist the breeder during the implementation steps of recurrent selection was observed from the study of Tardin et al. (2007), where the authors used molecular information to identify the most divergent genotypes in two corn populations in a full-sib reciprocal recurrent selection (FSRRS) program, seeking to maximize the genetic gains through exploration of heterosis.

The FSRRS, as proposed by Hallauer and Eberhart (1970), is composed of three stages: the generation of full-sib progenies of inter-populations and their $\mathrm{S}_{1}$ progenies, the evaluation of the full-sib progenies, and the recombination of $S_{1}$ progenies corresponding to the superior full-sib progenies. DNA markers have been used in a sample of superior $\mathrm{S}_{1}$ progenies in order to identify those progenies that are more divergent within both intra- and inter-populations. Thus, the recombinant progenies are both agronomically superior and divergent, contributing to heterosis.

The corn breeding program of the North Fluminense State University (UENF), involving CIMMYT and Piranão populations, has been working on the effectiveness of the FSRRS monitored by molecular markers (Tardin et al., 2007; da Cunha et al., 2012; Berilli et al., 2011, 2013). This tool was used to aid the FSRRS program in the eighth cycle using RAPD 
markers (Tardin et al., 2007), followed by AFLP markers in the ninth cycle (Gabriel, 2009), and ISSR markers in the tenth and twelfth cycles (Berilli et al., 2011; da Cunha et al., 2012). The effectiveness of this methodology was indicated by the release and registration with the Ministry of Agriculture, Livestock and Supply (MAPA) of two corn hybrids, 'UENF506-6' and 'UENF506-11', recommended for the North/Northwest Fluminense region. In 2004, Xia et al. (2004), in order to perform an analysis of genetic diversity in CIMMYT maize inbred lines, suggested the use of molecular markers in RRS programs to achieve greater success in the selection of divergent and productive individuals.

Among the DNA markers available, microsatellites (SSR) have been commonly used for analysis of genetic structure of plant populations due to their multi-allelic nature, codominance, and high polymorphism, allowing improvements in the efficiency of selection methods, contributing significantly to genetic gains. An alternative methodology for the development of SSR markers is the analysis of sequences from public databases or restricted data using computational resources. These sequences are mostly transcribed sequences called ESTs (expressed sequence tags). For microsatellites identified in transcribed sequences, locus-specific primers flanking these repeats can be defined and the region containing the SSR amplified (Cho et al., 2000). The EST-SSR markers have been widely used as a powerful molecular genetic tool due to their high level of transferability, close association with genes of known function, and low-cost development with the availability of public databases (Zhang et al., 2014).

Thus, the objective of this study was to use EST-SSR markers to estimate the genetic diversity in progeny derived from FSRRS of a maize program to assist in the selection step of the most divergent genotypes to compose the recombination blocks. The expectation is to maximize the genetic gains in the subsequent cycles of the breeding program, given that intraand inter-population differences are directly related to the functional genome, increasing the expectation that these differences reflect greater heterosis in future hybrids.

\section{MATERIAL AND METHODS}

For the genetic molecular characterization, 20 EST-SSR loci were analyzed in 80 genotypes ( $\mathrm{S}_{1}$ progenies), 40 from each population (CIMMYT and Piranão). These genotypes correspond to the top 40 full-sib progenies, are in the thirteenth recurrent selection cycle, and were selected in the agronomic evaluation step from a total of 210 previously evaluated genotypes.

Part of the $\mathrm{S}_{1}$ seeds was seeded in 5-L pots kept in a greenhouse. The genetic material for DNA extraction was collected in a bulk of 10 seedlings from each $\mathrm{S}_{1}$ progeny properly identified and taken to an Ultra-freezer at $-86^{\circ} \mathrm{C}$. Subsequently, each collected sample was separately macerated with liquid nitrogen to obtain a fine powder and an aliquot of approximately $0.1 \mathrm{~g}$ was transferred to a microtube. This sample was used for DNA extraction using the DNA Extraction Plant Genomics YGP 100 kit-RBC (BioAmerica, Linden, NJ, USA), following the manufacturer protocol. After extraction, the DNA was quantified using a NanoDrop ${ }^{\circledR}$ system and the quality was evaluated on a $0.8 \%$ agarose gel.

DNA amplification reactions were performed in a final volume of $30 \mu \mathrm{L}$ containing $30 \mathrm{ng}$ DNA, $6 \mu \mathrm{L} 5 \mathrm{X}$ reaction buffer, $1.5 \mathrm{mM} \mathrm{MgCl}, 200 \mathrm{mM}$ of each dNTP, $0.5 \mathrm{mM}$ of each primer (Sigma, USA), and 0.75 U Taq DNA polymerase (Go Taq Flexi, Promega, USA). Twenty polymorphic EST-SSR primers were selected. These primers were developed 
and mapped by Sharopova et al. (2002) and obtained using an NCBI search (National Center for Biotechnology Information) on page "Map View" (http://www.ncbi.nlm.nih.gov/projects/ mapview/maps.cgi?taxid=4577\&chr=1) (Table 1). Amplifications were carried out using the "touchdown" technique in an Eppendorf thermocycler, in which the temperature for pairing of the primers was initiated at $5^{\circ} \mathrm{C}$ above the optimum temperature and decreased by $1{ }^{\circ} \mathrm{C}$ for the first five cycles of amplification to the desired temperature. The cycle program consisted of $94^{\circ} \mathrm{C}$ for $4 \mathrm{~min} ; 94^{\circ} \mathrm{C}$ for $1 \mathrm{~min} ; \mathrm{Y}^{\circ} \mathrm{C}$ with a reduction of $1^{\circ} \mathrm{C}$ per cycle for $1 \mathrm{~min} ; 72^{\circ} \mathrm{C}$ for 3 $\min$ (for the first five cycles); $94^{\circ} \mathrm{C}$ for $1 \mathrm{~min} ; \mathrm{Y}^{\circ} \mathrm{C}$ for $1 \mathrm{~min} ; 72^{\circ} \mathrm{C}$ for $3 \mathrm{~min}$ (for 30 cycles); $72^{\circ} \mathrm{C}$ for $7 \mathrm{~min}$, where $\mathrm{Y}=$ annealing temperature defined for each primer (Table 1).

Next, the amplification products were distributed in specific 96-well plates for capillary electrophoresis using an Advance FS96 machine, together with markers containing fragments of 10 and $500 \mathrm{bp}$. On the sample plate, 250-bp DNA ladder (Invitrogen, USA) was added to $\mathrm{H} 12$ well to determine the size of the amplified fragments. Capillary electrophoresis was undertaken at an electric current of $7.5 \mathrm{~kW}$, where the DNA was subjected to a run of 140 $\mathrm{min}$. The data obtained from the amplification of the SSR primers were converted into numerical code for each allele per locus according to the procedure used by Ramos et al. (2011).

For molecular analysis, the estimated genetic diversity, the observed heterozygosity $\left(H_{\mathrm{O}}\right)$ for the group of genotypes in question, the polymorphism information content (PIC), and the inbreeding coefficient (F), were obtained using the PowerMarker software v3.25 (Liu and Muse, 2005). The GENES (Cruz, 2013) software was used to obtain the genetic dissimilarity matrix through the weighted index, as well as to analyze the genetic variability within and between groups using analysis of molecular variance (AMOVA) (Excoffier et al., 2005). A graphical dispersion of genotypes was also accomplished based on the analysis of principal coordinate method, as well as the analysis of allele frequency, using the GenAlEx 6.3 software (Peakall and Smouse, 2009).

\section{RESULTS AND DISCUSSION}

From the analysis of 20 EST-SSR loci, a total of 93 alleles, with allele numbers per locus ranging from 2 to 8 and an average of 4.65, were obtained (Table 1). Previous studies involving the use of molecular markers in the same breeding program consisted of analyses using dominant markers, such as RAPDs (Tardin et al., 2007) and ISSRs (Berilli et al., 2011; da Cunha et al., 2012), which had mean values of polymorphic alleles per primer of 5.43, 8.77 and 4.04, respectively. Such markers are multi-locus and have dominant inheritance, with the average number of alleles per primer corresponding to the polymorphism of several loci dispersed randomly in the genome. Even considering the difference in the nature of the genetic markers used in previous cycles and those used in the present study, we found similar and even superior results, with the polymorphism reported in this cycle from functional regions of the genome, demonstrating the potential of this technique to assist in recurrent selection programs.

By analyzing the PIC, it was possible to quantify the genetic polymorphism of each locus in the population. The PIC shows the informativeness of loci and their potential to detect differences between genotypes based on their genetic relationships (Rajendran et al., 2014). According to Botstein et al. (1980), a locus can be classified as highly informative when the value of PIC is greater than 0.5 , moderately informative when the value ranges from 0.5 to 0.25 , and not informative when less than 0.25 . In this study, of 20 microsatellite loci analyzed, $14(70 \%)$ can be considered highly informative. The maximum PIC was 0.76 for the bip2 
locus, while the lowest value (0.27) was observed for the umc1108 locus, and the mean PIC was 0.55 (Table 1). This mean PIC value indicates high levels of polymorphism of the analyzed loci, although some studies have reported low to medium levels of polymorphism for EST-SSRs (Zhang et al., 2014). Studies have attributed this low functional polymorphism of selection against changes in conserved regions of the EST-SSR markers (Scott et al., 2000).

No previous reports were found that report the use of EST-SSR markers for analyzing genetic relationships in maize; however, the average PIC value determined in our study was higher than some reported results in the literature based on genomic SSR markers, such as those reported by Wende et al. (2013) (0.54) and Heckenberger et al. (2002) (0.58), and below the values found in studies by Rajendran et al. (2014) (0.81) and Garcia et al. (2004) (0.89). However, it is important to note that estimates of PIC are inherent to the loci analyzed, as well as the structure of the studied population.

Table 1. EST-SSR primers and their chromosomal location (CL), distance (cM) from the centromere, annealing temperatures $(\mathrm{TM})$, number of alleles $\left(N_{\mathrm{A}}\right)$, size of alleles, and polymorphic information content (PIC).

\begin{tabular}{|c|c|c|c|c|c|c|}
\hline Locus & $\mathrm{CL}$ & $\mathrm{cM}$ & $\mathrm{TM}\left({ }^{\circ} \mathrm{C}\right)$ & $N_{\mathrm{A}}$ & Size Min-Max & PIC \\
\hline umc1948 & 1 & 82.6 & 53.2 & 4 & 143-196 & 0.627 \\
\hline umc1917 & 1 & 335.0 & 68.1 & 3 & $163-204$ & 0.562 \\
\hline umc 2149 & 1 & 798.4 & 58.1 & 5 & $168-230$ & 0.484 \\
\hline umc1108 & 2 & 358.6 & 60.8 & 2 & $145-180$ & 0.279 \\
\hline ckol & 3 & 97.0 & 53.2 & 4 & $124-147$ & 0.503 \\
\hline umc1135 & 3 & 466.4 & 53.2 & 2 & $125-144$ & 0.310 \\
\hline umc 2152 & 3 & 616.9 & 60.8 & 5 & $170-210$ & 0.569 \\
\hline umc1969 & 4 & 242.1 & 60.8 & 6 & $80-137$ & 0.733 \\
\hline umc1031 & 4 & 276.3 & 60.8 & 4 & $114-149$ & 0.398 \\
\hline bip2 & 4 & 669.1 & 60.8 & 6 & $116-170$ & 0.762 \\
\hline $\operatorname{gln} 4$ & 5 & 469.2 & 58.1 & 6 & $253-285$ & 0.697 \\
\hline umc 1250 & 6 & 228.6 & 53.2 & 5 & $170-206$ & 0.643 \\
\hline umc 2170 & 6 & 392.9 & 60.8 & 4 & $145-196$ & 0.627 \\
\hline umc 1412 & 7 & 478.6 & 60.8 & 3 & $162-210$ & 0.452 \\
\hline umc 1268 & 8 & 452.0 & 53.2 & 4 & $104-165$ & 0.369 \\
\hline umc 1078 & 9 & 306.5 & 68.1 & 6 & $118-192$ & 0.662 \\
\hline umc 1714 & 9 & 514.1 & 60.8 & 6 & $126-185$ & 0.392 \\
\hline umc1739 & 10 & 177.4 & 63.5 & 8 & $114-163$ & 0.599 \\
\hline tip5 & 10 & 335.1 & 53.2 & 5 & $148-210$ & 0.704 \\
\hline umc 2126 & 10 & 452.1 & 68.1 & 5 & $155-204$ & 0.640 \\
\hline
\end{tabular}

In the search for quantification of genetic diversity within populations, many descriptive measures have been used, allowing inferences about the population structure, including the number of alleles, heterozygosity, and Shannon index. By analyzing the allele frequency of individuals from the CIMMYT and Piranão populations, the number of observed alleles ranged from 1 to 6 and 2 to 8, with an average of 3.65 and 4.35, respectively (Table 2). This is the first report of the application of functional SSR markers in the breeding of these two populations, in which higher allelic richness was observed in the Piranão population, indicating greater genetic diversity among individuals in this population. Xia et al. (2004), working with genomic SSR markers in CIMMYT maize inbred lines, obtained an average of 7.4 alleles per locus, ranging from 2 to 18. Nevertheless, it is noteworthy that, unlike the last work cited, in this current study, functional microsatellites (EST-SSR) were used, with which you would expect to find a lower level of polymorphism since they correspond to more conserved regions throughout the genome.

Genetic diversity was analyzed in this study using the Shannon index and mean values of 0.89 and 1.04 for the CIMMYT and Piranão populations were observed, respectively (Table 
2), confirming the results already determined by the average number of alleles per locus. The Shannon index, also called the Shannon-Wiener diversity index, is a diversity measure widely used in studies of populations (Amaral et al., 2013), which allows inferences to be made on the richness or genotypic diversity of populations. According to this index, the closer of the unit, the greater the diversity of the population. Based on the values obtained in this study for the two populations under consideration (CIMMYT-0.89 and Piranão-1.04) we can infer that there is sufficient genetic variability for continuity of this breeding program with a real possibility of genetic gains with selection in the coming cycles of reciprocal recurrent selection.

Table 2. Genetic diversity parameters of the CIMMYT and Piranão populations based on the 20 EST-SSR loci analyzed.

\begin{tabular}{lllc}
\hline Parameters & \multicolumn{1}{c}{ CIMMYT } & \multicolumn{1}{c}{ Piranão } & Overall mean \\
\hline$N_{\mathrm{A}}$ & $3.65(1-6)$ & $4.35(2-8)$ & 4.00 \\
$N_{\mathrm{E}}$ & $2.26(1.00-3.87)$ & $2.64(1.10-5.10)$ & 2.45 \\
$H_{\mathrm{E}}$ & $0.49(0.00-0.74)$ & $0.55(0.10-0.80)$ & 0.52 \\
$H_{\mathrm{O}}$ & $0.26(0.00-0.73)$ & $0.34(0.00-0.69)$ & 0.30 \\
$\mathrm{I}$ & $0.89(0.00-1.52)$ & $1.04(0.20-1.69)$ & 0.97 \\
$\mathrm{~F}$ & $0.47(-0.36-1.00)$ & $0.36(-0.34-1.00)$ & 0.41 \\
\hline
\end{tabular}

$N_{\mathrm{A}}=$ number of alleles; $N_{\mathrm{E}}=$ effective number of alleles; $H_{\mathrm{E}}=$ expected heterozygosity; $H_{\mathrm{O}}=$ observed heterozygosity; $\mathrm{I}=$ Shannon index; $\mathrm{F}=$ fixation index.

The expected heterozygosity in the populations ranged from 0 to 0.80 , with a mean of 0.52 , while $H_{\mathrm{O}}$ ranged from 0 to 0.73 , with a mean of 0.30 (Table 2). Among populations, the highest mean value for $H_{\mathrm{O}}$ was found in the Piranão population (0.34), while the CIMMYT population showed a mean value of 0.26 . Zhang et al. (2014) characterized genetic and genomic SSR markers in barley and found that heterozygosity values ranged from 0.08 to 0.69 and 0.39 to 0.78 , respectively. In the analysis of genetic diversity among accessions of watermelon using SSR markers, Mujaju et al. (2013) found an average heterozygosity of 0.12 for EST-SSR markers, which was lower than that found for genomic SSR markers. Although rare, there are reports in the literature of higher heterozygosity observations in EST-SSR markers in relation to genomic SSR markers, for example, in the study developed by Liu et al. (2010). These researchers found slightly higher values of $H_{\mathrm{O}}$ in EST-SSR loci (0.069) relative to genome (0.014) markers. Regardless of microsatellite genomic location, Liu and $\mathrm{Wu}$ (1998) emphasize that, although important parameters, neither diversity nor heterozygosity is a good indicator for predicting heterosis.

The analysis of the inbreeding coefficient $(\mathrm{F})$ of individuals showed values ranging between -0.36 and 1.00 in the CIMMYT population and -0.34 and 1.00 in the Piranão population, with mean values of 0.47 and 0.36 , respectively. This parameter is one of the most important in genetic populations because it measures the balance between homozygotes and heterozygotes, and the mean values are related to the observed allelic richness of the populations. As can be seen, the lowest level of heterozygosity in the CIMMYT population is a response to higher allelic fixation indicated by the inbreeding coefficient.

In breeding programs that aim to develop inbred lines, analysis of the inbreeding coefficient or fixation index, inferred from the level of homozygosity of individuals, is an alternative to speed up the process of obtaining inbred lines. However, in breeding programs such as recurrent selection, an increase in inbreeding can generate negative consequences since in this situation inbreeding can result in deleterious recessive alleles and reduced heterozygosity that 
can result in a loss of allelic diversity and consequently a reduction in the genetic variance of the populations, compromising the future genetic gains per cycle.

The genetic distance among the top 40 genotypes of each population was analyzed using the UPGMA clustering method based on the genetic distance matrix (Figure 1). Through analysis of the dendrogram it was possible to observe a clear distinction between populations, with the formation of two groups with an average distance of 0.42 . The first group consists exclusively of genotypes from the Piranão population, whereas the second group includes only genotypes from the CIMMYT population. This result is very satisfactory because it shows that over the cycles of RRS, especially those monitored by molecular markers, there is a genetic distance between populations in breeding, which can contribute to maximization of heterosis in future cycles. This fact is more evident when analyzing the results found by Tardin et al. (2007) and Berilli et al. (2011), where the authors found several "contaminants" in the groups formed, i.e., genotypes had Piranão groupings with CIMMYT genotypes and vice versa. This indicates the potential of the molecular markers used in this study to distinguish the populations analyzed.

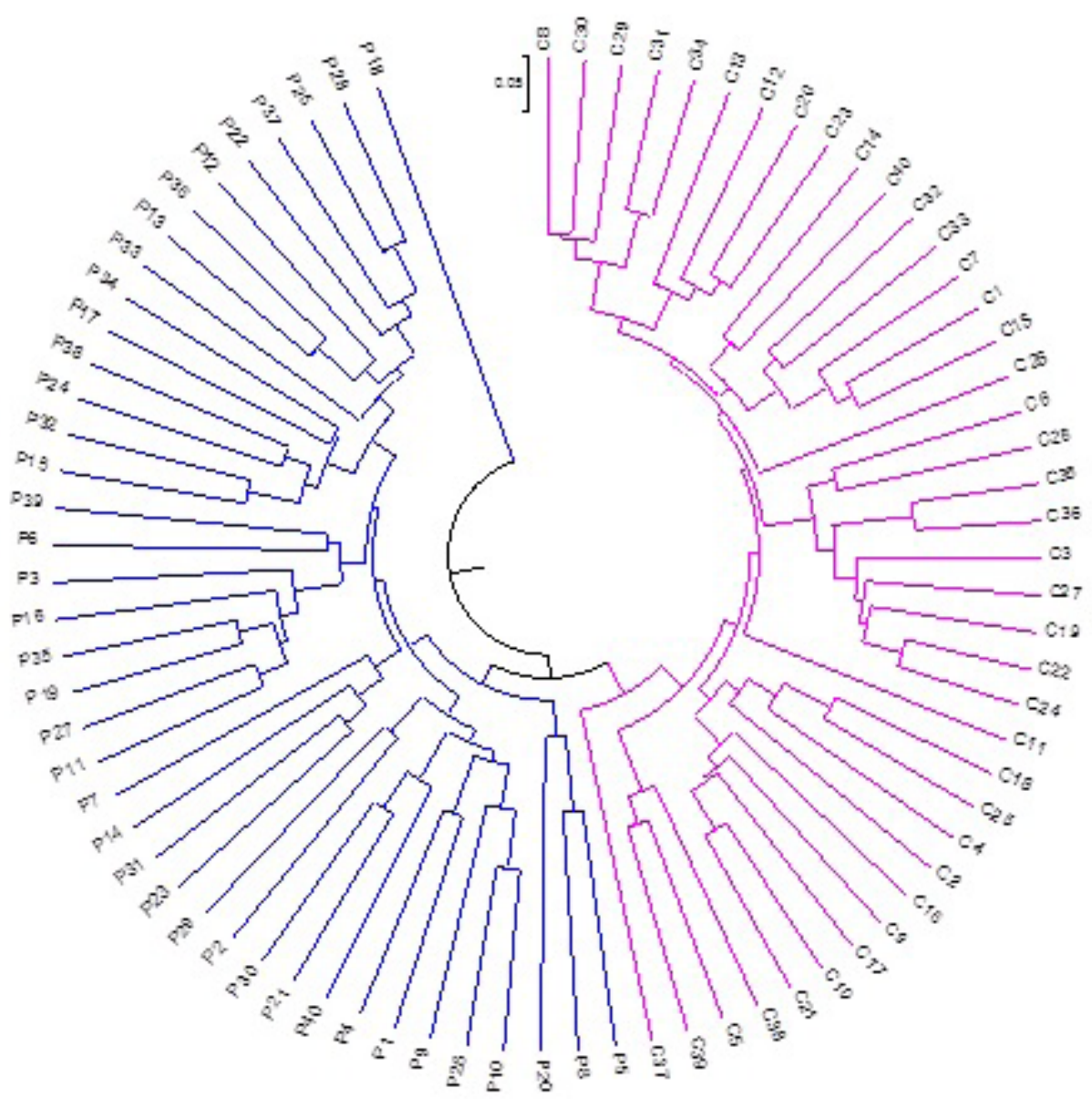

Figure 1. Dendrogram obtained using the UPGMA hierarchical method for $80 \mathrm{~S}_{1}$ progenies of maize. In blue are the 40 genotypes from the Piranão population and in rose are the 40 genotypes from the CIMMYT population. 
One factor that may have contributed to this clear distinction between the two populations is the existence of private or exclusive alleles, i.e., those that are present in only one population. Among the alleles identified, $24(25.8 \%)$ were unique, being detected in 13 of the 20 loci (Table 3). The frequencies of private alleles ranged from 0.694 to 0.013 in the loci cko1 and umc1739, respectively, both identified in the Piranão population. The locus that had the highest number of private alleles was umc1739, with 4 alleles with the following frequencies: $0.077,0.038,0.013$, and 0.026 . Among the populations, the Piranão population presented 19 unique alleles $(79.17 \%)$ and the CIMMYT population had 5 private alleles $(20.83 \%)$, demonstrating that part of the allelic richness of the Piranão population results from the presence of unique alleles in the population. Exclusive alleles may be helpful in the identification of cultivars. Liu et al. (2003), using SSR markers in maize inbred lines of importance for the improvement of temperate, tropical, and subtropical regions, also identified exclusive alleles. Working with populations of tropical maize in an RRS program, Pinto et al. (2003b) also found unique alleles in populations under study, being largely observed in the BR-106 population.

Table 3. Private alleles and their frequencies in the CIMMYT and Piranão populations for the 20 EST-SSR loci analyzed.

\begin{tabular}{lcc}
\hline Locus & & Population \\
\cline { 2 - 3 } & CIMMYT* & Piranão* \\
\hline umc2149 & - & 0.014 \\
cko1 & - & 0.028 \\
cko1 & - & 0.694 \\
cko1 152 & - & 0.222 \\
umc2152 & - & 0.122 \\
umc2152 & - & 0.068 \\
umc2152 & 0.083 & 0.189 \\
umc1031 & - & - \\
umc1031 & 0.013 & 0.041 \\
gln4 & - & - \\
umc1250 & - & 0.235 \\
umc1250 & - & 0.176 \\
umc1412 & - & 0.125 \\
umc1268 & 0.238 & 0.041 \\
umc1078 & - & - \\
umc1078 & 0.026 & 0.051 \\
umc1714 & - & - \\
umc1714 & - & 0.051 \\
umc1739 & - & 0.077 \\
umc1739 & - & 0.038 \\
umc1739 & - & 0.013 \\
umc1739 & 0.225 & 0.026 \\
tip5 & - & - \\
umc2126 & & 0.153 \\
\hline
\end{tabular}

*Frequency of private alleles using 40 individuals from each population.

Graphical representation of genetic divergence allows verification of the existence of significant variability among and within populations. In order to maximize intra-population variability and inter-population genetic distance, the EST-SSRs were used to eliminate 15 of the 40 genotypes from each population. These 40 genotypes were identified as the superior genotypes based on the selection index of the field plot test. To facilitate this step of eliminating less divergent genotypes, principal component analysis was performed with graphical dispersion of genetic diversity (Figure 2A). For this, we adopted the following criteria: elimination of genotypes near the other population and elimination of genetically similar genotypes 
inside the population, keeping those that were divergent with a higher mean grain yield. The quantification of this variability was obtained by AMOVA, where it was observed that of the total genetic variance, $27 \%$ was detected between populations and $73 \%$ within populations (Table 4) before the selection step. After the selection of genotypes, we observed an increase in the genetic variation between populations (35.69\%) with allocation of families according to their respective heterotic groups, and a slight decrease in genetic variation within populations (64.31\%). So, although it works with distinct populations, greater variability was observed among individuals within populations. This is a good result since one of the goals of the program is to maintain the genetic variability within, and increase the variability among, populations (Figure 2B).

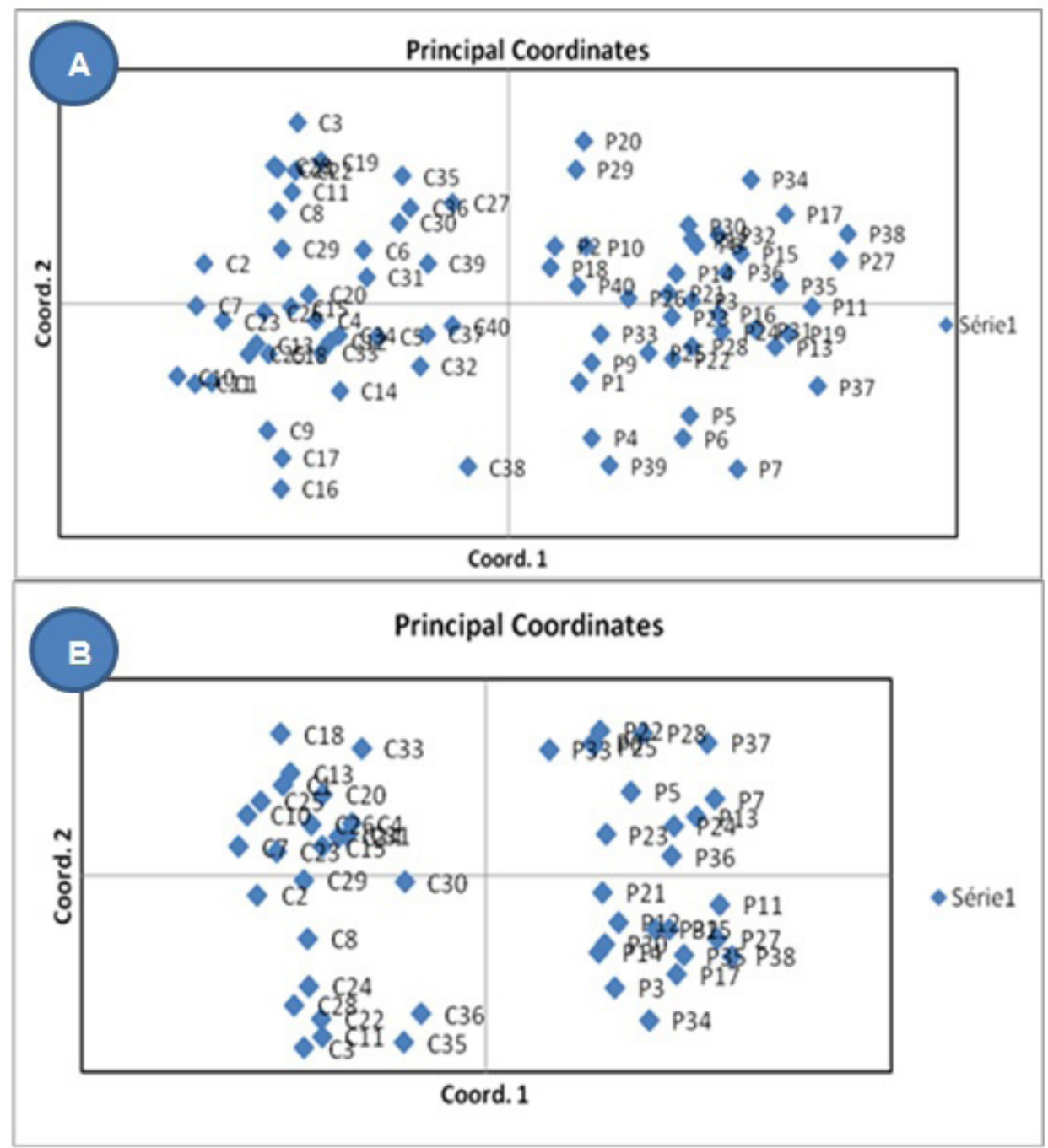

Figure 2. Graphical dispersion analysis using the principal coordinate method of 80 maize genotypes from two populations based on EST-SSR molecular markers, before selection (A) and after selection (B). 
Table 4. Analysis of molecular variance of the CIMMYT and Piranão populations before and after selection based on molecular genotyping.

\begin{tabular}{lrrccc}
\hline Source of variation & d.f. & MS & Variance components & Percentage & Probability \\
\hline Before selection & & & & & \\
Between populations & 1 & 13.7938 & 0.3234 & 27.3353 & $<0.001$ \\
Within populations & 78 & 0.8596 & 0.8596 & 72.6647 & $<0.001$ \\
Total & 79 & 1.0233 & 1.11829 & 100 & \\
After selection & 1 & 11.3889 & 0.4249 & 35.6898 & $<0.001$ \\
Between populations & 48 & 0.7657 & 0.7657 & 64.3102 & $<0.001$ \\
Within populations & 49 & 0.9825 & 1.1906 & 100 & \\
Total &
\end{tabular}

d.f. $=$ degrees of freedom; $\mathrm{MS}=$ mean square.

Results presented by Berilli et al. (2011), analyzing the tenth RRS cycle, show that $89.84 \%$ of the total genetic variance was within the CIMMYT and Piranão populations and only $10.16 \%$ was between populations before the selection stage, the latter value increased to $14.27 \%$ after selection of the most divergent genotypes. da Cunha et al. (2012), evaluating the eleventh RRS cycle, found $88.77 \%$ of genetic variance within and $11.23 \%$ between the CIMMYT and Piranão populations before selection, and $82.33 \%$ within and $17.67 \%$ between after selection. Based on these results, it can be observed that one of the main objectives of a program of recurrent selection has been achieved, i.e., the genetic variability within populations has been maintained at satisfactory levels, while the variability between populations has increased over cycles of selection, contributing to the longevity of the breeding program. From theoretical and experimental results, Melchinger (1999) demonstrated that the organization of germplasm into genetically divergent heterotic groups is a key aspect to a systematic and optimal exploitation of heterosis.

Considering that heterosis depends directly on the genetic distance between populations (Hallauer et al., 1988), we conclude that from the effectiveness of the markers used here that heterosis is expected to be enhanced in future hybrids derived from crossings between populations or between inbred lines derived from the resulting populations. This is expected since the EST-SSR markers detect functional diversity. Thus, such diversity may be more related to heterosis or hybrid vigor than markers accessing random regions of the genome.

There are several studies that have used genomic markers to associate heterosis in simple hybrids as a function of genetic distance between their parents but in most cases the correlation results have not been significant (Paterniani et al., 2008; Guimarães et al., 2009). Consequently, it is not possible to infer the performance of corn hybrids from the genetic divergence between inbred lines. Such results demonstrate that divergence is not always associated with heterosis, unless the distance is functional, i.e., that the marker locus is associated with expression of genes responsible for the trait of interest. According to Mohammadi et al. (2008), the use of markers not linked to the characteristic in the genetic distance estimator can be a possible reason for the low magnitude or poor correlation between genetic distance and heterosis. Bernardo (1992) suggests the use of markers closely linked to the chromosome segment that determines expression of the trait as a way to overcome this problem. This reinforces the importance of the present study with regard to functional markers associated with classical breeding procedures, contributing to increased consistency in the results related to dissimilarity or intra- and inter-population divergence, as well as for future study related to prediction of hybrid performance from the genetic distance between inbred lines. 
As can be seen, these analyses allowed efficient formation of the recombination block for the composition of the initial population of the 14th cycle of reciprocal recurrent selection. The results also demonstrate the effectiveness of the method for improving both populations and for the formation of inter-populational superior hybrids. Another important fact that deserves note is that the molecular genotyping of inbred lines also facilitates the procurement of recombinant inbred lines. Those lines that are more divergent, with high inbreeding coefficient, are perfect candidates to advance the generation in search of potential inbred candidate lines for progenitors of hybrids.

In this study, the genic SSR markers were effective in clustering genotypes into their respective populations. They were also effective in identifying high variability at both the intra- and inter-populational level. It is expected that such variability and genetic distance are more directly associated with heterosis of future hybrids, given the nature of the sampled genomic region, as well as providing higher genetic gain per cycle of RRS.

\section{ACKNOWLEDGMENTS}

Research supported by Fundação Carlos Chagas Filho de Amparo à Pesquisa do Estado do Rio de Janeiro, FAPERJ.

\section{REFERENCES}

Allard RW (1971). Princípios do melhoramento genético das plantas. Edgard Blucher, São Paulo.

Amaral LP, Ferreira RA, Lisboa GS, Longhi SJ, et al. (2013). Variabilidade espacial do índice de diversidade de ShannonWiener em floresta ombrófila mista. Sci. For. 41: 83-93.

Berilli APCG, Pereira MG, Gonçalves LSA, da Cunha KS, et al. (2011). Use of molecular markers in reciprocal recurrent selection of maize increases heterosis effects. Genet. Mol. Res. 10: 2589-2596.

Berilli APCG, Pereira MG, Tindade RS, da Costa FR, et al. (2013). Response to the selection in the 11th cycle of reciprocal recurrent selection among full-sib families of maize. Acta Sci. 35: 435-441.

Bernardo R (1992). Relationship between single-cross performance and molecular marker heterozygosity. Theor. Appl. Genet. 83: 628-634.

Botstein D, White RL, Skolnick M and Davis RW (1980). Construction of a genetic linkage map in man using restriction fragment length polymorphisms. Am. J. Hum. Genet. 32: 314-331.

Cho YG, Ishii T, Temnykh S, Chen X, et al. (2000). Diversity of microsatellites derived from genomic libraries and GenBank sequences in rice (Oryza sativa L.). Theor. Appl. Genet. 100: 713-722.

Cruz CD (2013). GENES - a software package for analysis in experimental statistics and quantitative genetics. Acta Sci. 35: 271-276.

da Cunha KS, Pereira MG, Gonçalves LSA, Berilli APCG, et al. (2012). Full-sib reciprocal recurrent selection in the maize populations Cimmyt and Piranão. Genet. Mol. Res. 11:3398-3408.

De Koeyer DL, Phillips RL and Stuthman DD (2001). Allelic shifts and quantitative trait loci in a recurrent selection population of oat. Crop Sci. 41: 1228-1234.

Excoffier L, Laval G and Schneider S (2005). Arlequin (version 3.0): An integrated software package for population genetics data analysis. Evol. Bioinform. 1: 47-50.

FAO (2012). FAO Statistical Database. Rome. Available at [http://www.fao.org/docrep/011/ai82e/ai482e04.htm]. Accessed March 15, 2013.

Gabriel APC (2009). Seleção recorrente recíproca em famílias de irmãos completos em milho (Zea mays L.) assistida por marcadores moleculares. Tese (Mestrado em Genética e Melhoramento de Plantas),UENF, Campos dos Goytacazes.

Garcia AAF, Benchimol LL, Barbosa AMM, Geraldi IO, et al. (2004). Comparison of RAPD, RFLP, AFLP and SSR markers for diversity studies in tropical maize inbred lines. Genet. Mol. Biol. 4: 579-588.

Guimarães CT, Schuster I, Magalhães JV and de Souza Júnior CL (2009). Marcadores moleculares no melhoramento. 2nd edn. In: Marcadores moleculares (Borém A and Caixeta ET, eds.). UFV, Viçoca, 129-176.

Hallauer AR and Eberhart SA (1970). Reciprocal full-sib selection. Crop Sci. 10: 315-316. 
Hallauer AR, Carena MJ and Miranda Filho JB (1988). Quantitative genetics in maize breeding. 3rd edn. Iowa State University Press, Iowa.

Heckenberger M, Bohn M, Ziegle JS, Joe LK, et al. (2002). Variation of DNA fingerprints among accessions within maize inbred lines and implications for identification of essentially derived varieties. I. Genetic and technical sources of variation in SSR data. Mol. Breeding 10: 181-191.

Labate JA, Lamkey KR, Lee M and Woodman WL (1997). Molecular genetic diversity after reciprocal recurrent selection in BSSS and BSCB1 maize populations. Crop Sci. 37: 416-423.

Liu K and Muse SV (2005). PowerMarker: an integrated analysis environment for genetic marker analysis. Bioinformatics 21: $2128-2129$

Liu K, Goodman M, Muse S, Smith JS, et al. (2003). Genetic structure and diversity among maize inbred lines as inferred from DNA microsatellites. Genetics 165: 2117-2128.

Liu XC and Wu JL (1998). SSR heterogenic patterns of parents for marking and predicting heterosis in rice breeding. Mol. Breed. 4: 263-268.

Liu Y, Li Y, Zhou G, Uzokwe N, et al. (2010). Development of soybean EST-SSR markers and their use to assess genetic diversity in the subgenus Soja Agr. Sci. China 9: 1423-1429.

Melchinger AE (1999). Genetic diversity and heterosis. In: The genetics and exploitation of heterosis in crops: An International Symposium, 17-22 August 1997, Mexico City, Mexico: Book of Abstracts (Gerdes JT, Coors JG and Pandey S, eds.). American Society of Agronomy, Madison, 99-118.

Mohammadi SA, Prasanna BM, Sudan C and Singh NN (2008). SSR heterogenic patterns of maize parental lines and prediction of hybrid performance. Biotechnol. Biotec. Eq. 22: 541-547.

Mujaju C, Sehic J and Nybom H (2013). Assessment of EST-SSR markers for evaluating genetic diversity in watermelon accessions from Zimbabwe. Am. J. Plant Sci. 4: 1448-1456.

Paterniani MEAGZ, Guimarães PS, Lurdes RR, Gallo PB, et al. (2008). Capacidade combinatória, divergência genética entre linhagens de milho e correlação com heterose. Bragantia 67: 639-648.

Peakall R and Smouse P (2009). GenAlEx Tutorials - Part 1: Introduction to frequency based population genetic analysis. Australian National University, Australia.

Pinto LR, Vieira MLC, Souza CL and Souza AP (2003a). Reciprocal recurrent selection effects on the genetic structure of tropical maize populations assessed at microsatellite loci. Genet. Mol. Biol. 26: 355-364.

Pinto LR, Vieira MLC, Souza CL, Silva RM (2003b). Isoenzymatic variability in tropical maize populations under reciprocal recurrent selection. Sci. Agric. 60: 291-297.

Rajendran A, Muthiah A, Joel J, Shanmugasundaram P, et al. (2014). Heterotic grouping and patterning of quality protein maize inbreds based on genetic and molecular marker studies. Turk. J. Biol. 38: 10-20.

Ramos HC, Pereira MG, Silva FF, Gonçalves LS, et al. (2011). Genetic characterization of papaya plants (Carica papaya L.) derived from the first generation of backcross. Genet. Mol. Res. 10: 393-403.

Santos PG, Juliatti FC, Buiatti AL and Hamawaki OT (2002). Avaliação do desempenho agronômico de híbridos de milho em Uberlândia, MG. Pesqui. Agropecu. Bras. 37: 597-602.

Scott KD, Eggler P, Seaton G, Rossetto M, et al. (2000). Analysis of SSRs derived from grape ESTs. Theor. Appl. Genet. 100: 723-726.

Sharopova N, McMullen MD, Schultz L, Schroeder S, et al. (2002). Development and mapping of SSR markers for maize. Plant Mol. Biol. 48: 463-81.

Tardin FD, Pereira MG, Gabriel APC, Amaral Júnior AT, et al. (2007). Selection index and molecular markers in reciprocal recurrent selection in maize. Crop Breed. Appl. Biotechnol. 7: 225-233.

Wende A, Shimelis H, Derera J, Mosisa W, et al. (2013). Genetic interrelationships among medium to late maturing tropical maize inbred lines using selected SSR markers. Euphytica 191: 269-277.

Xia XC, Reif JC, Hoisington DA, Melchinger AE, et al (2004). Genetic diversity among CIMMYT maize inbred lines investigated with SSR markers. Crop Sci. 44: 2230-2237.

Zhang M, Mao W, Zhang G and Wu F (2014). Development and characterization of polymorphic EST-SSR and genomic SSR markers for Tibetan annual wild barley. PLOS ONE 9: e94881. doi:10.1371/journal.pone.0094881. 